\title{
Pengaruh Sosialisasi Pembelajaran Online terhadap Tingkat Keaktifan Siswa SD di Desa Sumberagung Lamongan
}

\author{
The Effect of Online Learning Socialization on the Activity Level of Elementary School \\ Students in Sumberagung Village, Lamongan
}

Nur Nafi’iyah ${ }^{1 凶}$, Ika Purnama Sari²

${ }^{1}$ Prodi Teknik Informatika Fakultas Teknik Universitas Islam Lamongan

${ }^{2}$ Fakultas Perikanan Universitas Islam Lamongan

$\bowtie$ mynaff26@gmail.com
Riwayat naskah:

Diterima: 7 Juli 2020

Disetujui: 19 November 2020

Diterbitkan: 11 Januari 2021

\begin{abstract}
Online learning is the newest way of learning, where students can access the material directly even in far places. Online learning is a way to deliver material without having to meet with students. The purpose of this activity is to find a relationship between online learning and the activeness of elementary school students in Sumberagung Mantup Lamongan. The data used in this study, namely: data on the results of student activity in accessing online learning, ranging from participation in accessing e-learning and reading material, participating in discussions in online learning. Student data used as many as 133 students, and the variables of this study, namely the number of values involved in the discussion, the total value of reading material. The results of this study indicate that there is no correlation between students' interest in reading online learning and discussion activeness at online learning, with a correlation value of -0.024.
\end{abstract}

Keywords: correlation; discussion; e-learning; interest in reading.

Abstrak: Pembelajaran secara online merupakan cara pembelajaran terbaru, di mana peserta didik dapat mengakses materi secara langsung walaupun di tempat jauh. Pembelajaran online merupakan cara menyampaikan materi tanpa harus bertatap muka dengan peserta didik. Tujuan dari kegiatan ini, yaitu mencari hubungan antara pembelajaran online dengan keaktifan siswa SD di Sumberagung Mantup Lamongan. Data yang digunakan dalam penelitian ini, yaitu: data hasil keaktifan siswa dalam mengakses pembelajaran online, mulai dari keikutsertaan dalam mengakses e-learning dan membaca materi, ikut serta dalam berdiskusi dalam pembelajaran online. Data siswa yang digunakan sebanyak 133 siswa, dan variabel dari penelitian ini, yaitu jumlah nilai ikut berdiskusi, jumlah nilai membaca materi. Hasil penelitian ini menunjukkan bahwa tidak adanya korelasi antara minat membaca siswa dalam pembelajaran online terhadap keaktifan berdiskusi pada pembelajaran online, dengan nilai korelasi -0,024.

Kata kunci: diskusi; korelasi; minat baca; pembelajaran online. 


\section{Pendahuluan}

Pendidikan merupakan ujung tombak dari pembangunan negara. Dengan sumber daya manusia yang berpendidikan maka Indonesia dapat berkembang dan maju. Pendidikan yang baik adalah pendidikan yang menanamkan karakter dan kepribadian yang baik. Pendidikan yang berkarakter contohnya menanamkan jiwa toleransi, jiwa gotong royong, dan jiwa kejujuran. Cara menerapkan karakter jujur adalah mengerjakan soal ujian dengan tidak mencontek dari teman. Cara mengajar dan mendidik selalu berubah mengikuti kurikulum yang digunakan. Dengan berbagai macam cara mengajar dan mendidik siswa diharapkan dapat membentuk dan menanamkan karakter yang baik kepada siswa. Perubahan kurikulum dan metode pendidikan tujuan utamanya adalah meningkatkan kemampuan siswa serta menanamkan jiwa yang berkarakter.

Perkembangan teknologi merupakan salah satu media yang dapat digunakan untuk melakukan pengajaran atau pendidikan, misalnya dengan pemanfaatan multimedia dalam pembelajaran yang dapat meningkatkan efektifitas belajar (Ardiansyah \& Asfiyak, 2020) atau dengan menjalankan pembelajaran secara daring (online) (Purnama, 2020). Tujuan diadakan pembelajaran online adalah membangun jiwa jujur dan semangat kepada siswa dalam belajar. Siswa dapat belajar dan dapat mengakses materi atau tugas yang diberikan secara online di rumah. Dengan pembelajaran online, siswa dilatih untuk bersikap jujur mengerjakan di rumah tanpa harus mencontoh tugas teman, dan semangat mengerjakan walaupun tidak bersama guru. Sedangkan guru dapat memantau secara berkala setiap tugas/pekerjaan dari siswa secara online.

Pembelajaran online dapat dijadikan sebagai metode pembelajaran yang baik karena faktor fleksibel, skala, dan fungsional yang dapat memudahkan kegiatan belajar mengajar. Sehingga kegiatan belajar mengajar dapat dilakukan di manapun dan kapanpun (Yudie Irawan, Nanik Susanti, Wiwit Agus Triyanto, 2015). Kegiatan pembelajaran online sebagai media pembelajaran yang bertujuan untuk memberikan tugas ke siswa agar dapat dikerjakan dan diakses di rumah. Di mana guru dapat memantau keaktifan siswa saat di rumah. Sedangkan saat di sekolah guru dapat secara langsung berinteraksi dan bertatap muka untuk membahas materi dan tugas hasil kerjaan siswa melalui e-learning.

Pembelajaran online merupakan suatu media belajar yang membutuhkan akses internet agar dapat belajar mengajar. Edmodo adalah salah satu aplikasi yang bisa digunakan untuk membangun pembelajaran online. Edmodo merupakan aplikasi yang digunakan untuk membuat kelas virtual sesuai kondisi belajar mengajar di kelas. Guru dapat membuat kelas-kelas serta membuat tugas serta kuis sesuai pelajaran yang diberikan secara konvensional (Putranti, 2013).

Di masa pandemi seperti ini juga pembelajaran secara online dapat dilaksanakan dengan baik. Terbukti dari seluruh jenjang pendidikan dari SD sampai perguruan tinggi melakukan pembelajaran secara online. Mulai dengan media Google Classroom, atau e-learning, atau Zoom, hingga yang sekedar menggunakan media WhatsApp.

Evaluasi pembelajaran secara online perlu dilakukan karena adanya kelemahan evaluasi pembelajaran secara konvensional. Adapun kelemahan evaluasi pembelajaran secara konvensional, yaitu: membutuhkan waktu dan biaya untuk mencetak instrumen, membutuhkan waktu dan biaya Untuk penilaian, membutuhkan umpan balik ke peserta dan proses evaluasi secara konvensional membuat para peserta ujian cemas karena harus menunggu penilaian selesai (Setemen, 2010). Dari kelemahan evaluasi pembelajaran secara konvensional maka dibutuhkan 
suatu sistem evaluasi online. Dengan diadakannya evaluasi pembelajaran secara online mampu menghemat waktu dan biaya, sehingga dapat memberikan hasil yang tepat dan cepat (Setemen, 2010).

Pembelajaran online membutuhkan akses internet agar bisa terhubung dalam jaringan media yang digunakan dalam pembelajaran. Pemanfaatan akses internet banyak digunakan untuk bersosialisasi, mencari informasi serta belajar. Dengan memanfaatkan akses internet diharapkan dapat mengembangkan pembelajaran secara online, sehingga dapat memperoleh informasi secara terus menerus tanpa dibatasi waktu dan tempat. Berdiskusi tidak harus secara langsung bertatap muka, melainkan dapat melalui pembelajaran online (Yuberti, 2015).

Pada penelitian Hanum (2013), proses pembelajaran e-learning pada SMK Telkom Sandhy Putra Purwokerto sesuai standar mutu. Di mana standar mutu yang dinilai, yaitu proses perencanaan pembelajaran yang baik $77,57 \%$, proses perancangan dan pembuatan materi yang baik $75,14 \%$, proses penyampaian materi secara online/e-learning yang baik $75 \%$.

Dari beberapa tempat diketahui telah menggunakan media pembelajaran secara online $(e-$ learning). Maka penelitian ini mengujicoba pembuatan media pembelajaran secara online pada SD Sumberagung Mantup Lamongan. Di mana materi hanya menyampaikan dasar-dasar teknologi informasi, serta tempat untuk berdiskusi. Tujuan penelitian ini, yaitu melihat keaktifan peserta dalam proses pembelajaran secara online dan keaktifan dalam berdiskusi secara online. Pembelajaran secara online sering kali pendidik dengan peserta didik tidak dapat secara langsung bertatap muka, sehingga membuat pendidik sulit menilai keaktifan peserta didik. Oleh karena itu perlu diberikan suatu komentar, form diskusi dalam setiap sub materi, agar dapat menilai keaktifan peserta didik dalam berdiskusi serta tanya jawab.

\section{Metode Penelitian}

Dalam penelitian ini, peneliti selalu memantau setiap kegiatan peserta didik dalam mengakses $e$ learning. Sistem akan merekap semua kegiatan peserta didik saat membaca materi dan diskusi secara online. Dari hasil rekap kegiatan membaca dan berdiskusi, maka didapatkan jumlah berapa kali siswa membaca dan berdiskusi dalam e-learning. Dari jumlah siswa membaca dan berdiskusi kemudian dinilai atau memberikan nilai terhadap jumlah peserta didik mengakses. Dan tahapan terakhir mencari dan menghitung nilai korelasi dari keaktifan siswa dalam membaca dan berdiskusi secara online.

Data yang digunakan dalam penelitian ini sebanyak 133 peserta didik seluruh siswa SD di Desa Sumberagung Mantup Lamongan, akan tetapi yang aktif dalam menggunakan e-learning sebanyak 69 siswa. Data peserta didik dalam Tabel 1.

Tabel 1 Daftar Peserta Didik

\begin{tabular}{|l|l|l|l|}
\hline \multicolumn{1}{|c}{ Nama } & No & \multicolumn{2}{c|}{ Nama } \\
\hline $\mathbf{1}$ & Nur Cholifah & $\mathbf{1 5}$ & Shinta Budi Pertiwi \\
\hline $\mathbf{2}$ & Siti Maimunah & $\mathbf{1 6}$ & Lili Widiani \\
\hline $\mathbf{3}$ & Elza Fitriani & $\mathbf{1 7}$ & Idul Hamkah \\
\hline $\mathbf{4}$ & Titik Widaryati & $\mathbf{1 8}$ & Siska Nur Apriyani \\
\hline $\mathbf{5}$ & Lilis Sumiyati & $\mathbf{1 9}$ & Winda Susanti \\
\hline
\end{tabular}


Pengaruh Sosialisasi Pembelajaran Online terhadap Tingkat Keaktifan Siswa SD di Desa Sumberagung Lamongan / Nur Nafi'iyah, Ika Purnama Sari

\begin{tabular}{|c|c|c|c|}
\hline 6 & Artiwulan Suciati & 20 & Elik Sujarwati \\
\hline 7 & Oky Herlingga & 21 & Ali Khusen \\
\hline 8 & Ari Restu Wibowo & 22 & Nira Karlina \\
\hline 9 & Herawati Dwi Ratna Sari & 23 & Winda Nirmala \\
\hline 10 & Tiara Monica & 24 & Tri Minarsih \\
\hline 11 & Aulia Ulfah & 25 & Nurmasyitah \\
\hline 12 & Zhauhar Latifah & 26 & Mardiyanti Waruwu \\
\hline 13 & Taufan Ekel & 27 & Firdha Lisdini Memiadi \\
\hline 14 & Ahmad Hidayat & 28 & Efrawati \\
\hline 29 & Rike Handayani. & 73 & Dewi Sopiana \\
\hline 30 & Iwandi & 74 & Nurjanah \\
\hline 31 & Karlena & 75 & Gagasabila Wiwaha \\
\hline 32 & Eni Kustika Dewi & 76 & Abdul Qorib \\
\hline 33 & Septian Ardi & 77 & Sri Yanik \\
\hline 34 & Novi Efriza & 78 & Puji Dwi Astutik \\
\hline 35 & Ririn Risdyaningsih & 79 & Suwarno \\
\hline 36 & Yuni Arsih & 80 & Ildha Dina Risandy \\
\hline 37 & Lusi Lawati & 81 & Siswanto \\
\hline 38 & Indra Cahyadi & 82 & Mohamad Abdul Rozaq \\
\hline 39 & Ani Nurmawati & 83 & Siti Nur Azizah \\
\hline 40 & Tia Rustia & 84 & Okta Resi Ary Anggraeni \\
\hline 41 & Nyai Nursam & 85 & Diana Novianti Cahyaning \\
\hline 42 & Irna Nurhasanah & 86 & Nico Risqianto \\
\hline 43 & Eka Nursakinah & 87 & Ni Luh Eka Werdhi Astity \\
\hline 44 & Intan Fadilah & 88 & Anak Agung Nila $p$ \\
\hline 45 & Tama Nadia Oktapiani & 89 & Ilham Zaini \\
\hline 46 & Nur Risma Gustiawati & 90 & Joni Ramdani \\
\hline 47 & m.Farhan Saban & 91 & Nia Septiana \\
\hline 48 & Charles Tirta & 92 & Andi Kukuh Arya \\
\hline 49 & Riska Kusuma Dewi & 93 & Sadarudin Usman \\
\hline 50 & Nana Supriatna & 94 & George Andry Faah \\
\hline 51 & Egha Putriyana & 95 & Ebriliani Etika Hari \\
\hline 52 & Dede Supriadi & 96 & Theresia Dul'a Avin \\
\hline 53 & Samuel Ega Oktavianus & 97 & Maria Nona Yanti \\
\hline 54 & Nur Praptiwi Mita Hapsari & 98 & Siblina Sedo \\
\hline 55 & Dian Dwi Martanto & 99 & Marselino Edi Ucuk \\
\hline 56 & Sri Widyawati & 100 & Suhartina \\
\hline 57 & Ita Nurafiyah & 101 & Anandah Febri Yustika a \\
\hline 58 & Uswatun Khasanah & 102 & Fitri Erviana \\
\hline 59 & Siti Magfiroh & 103 & Ipa Soraya Achmad \\
\hline 60 & Dewi Tri Pujiastuti & 104 & Lili \\
\hline 61 & Anindya Agam Saputri & 105 & Lutfiana Ibrahim \\
\hline 62 & Eli Sumiyati & 106 & Arfawati Arifin \\
\hline 63 & Rika Fatayat & 107 & Mufliha \\
\hline
\end{tabular}




\begin{tabular}{|l|l|l|l|}
\hline $\mathbf{6 4}$ & Raszyid Ahmad Setiawan & $\mathbf{1 0 8}$ & Jaheriah \\
\hline $\mathbf{6 5}$ & Subekti Hariyanto & $\mathbf{1 0 9}$ & Rahmania \\
\hline $\mathbf{6 6}$ & Awalia Rahimi & $\mathbf{1 1 0}$ & Tati Cucu Rahayu \\
\hline $\mathbf{6 7}$ & Wiwit Pertiwi & $\mathbf{1 1 1}$ & Dwi Indriyani \\
\hline $\mathbf{6 8}$ & Iis Topaningsih & $\mathbf{1 1 2}$ & Iswan Onunu \\
\hline $\mathbf{6 9}$ & Syarifah Kiki Amelia & $\mathbf{1 1 3}$ & Atifa Lolilatu \\
\hline $\mathbf{7 0}$ & Fitri Yunita & $\mathbf{1 1 4}$ & Titin s. Daud \\
\hline $\mathbf{7 1}$ & Raydendo & $\mathbf{1 1 5}$ & Eka Nur Oktaviana \\
\hline $\mathbf{7 2}$ & Khairunnida & $\mathbf{1 1 6}$ & Eddy Triyanto \\
\hline $\mathbf{1 1 7}$ & Zeiful Rahman & $\mathbf{1 2 6}$ & Bilqis Anisah \\
\hline $\mathbf{1 1 8}$ & Nonik Meyda Riska Swantari & $\mathbf{1 2 7}$ & Rachmat Kurnianto \\
\hline $\mathbf{1 1 9}$ & Rizki Amanda & $\mathbf{1 2 8}$ & Aan Darwati \\
\hline $\mathbf{1 2 0}$ & Ario Maulana Pinem & $\mathbf{1 2 9}$ & Nuri Agil Tiasari \\
\hline $\mathbf{1 2 1}$ & Donni Rusdi Agustaf & $\mathbf{1 3 0}$ & Hanifa Dilla Ayu Nissa \\
\hline $\mathbf{1 2 2}$ & Imas Halimatun Sadiah & $\mathbf{1 3 1}$ & Rohyani \\
\hline $\mathbf{1 2 3}$ & Sri Astutik & $\mathbf{1 3 2}$ & Mohamad Eka Purnama \\
\hline $\mathbf{1 2 4}$ & Imam Lukyto & $\mathbf{1 3 3}$ & Irbad \\
\hline $\mathbf{1 2 5}$ & Dari Mulyani & & \\
\hline
\end{tabular}

Dari data Tabel 1 kemudian dilakukan pengecekan jumlah berapa kali siswa mengklik untuk membaca materi dan berdiskusi secara online dalam e-learning. Cara melihat jumlah klik dari siswa melihat atau berdiskusi secara online dalam e-learning berdasarkan log yang ada di Moodle. Rekap kegiatan membaca dan berdiskusi dalam Tabel 2.

Tabel 2 Total Rekap Forum Diskusi dan Membaca

\begin{tabular}{|c|c|c|c|c|c|c|c|c|c|c|c|}
\hline No & $\begin{array}{c}\text { mina } \\
\mathbf{t} \_b a c \\
\mathbf{a}\end{array}$ & $\begin{array}{c}\text { disk } \\
\text { usi }\end{array}$ & No & $\begin{array}{c}\text { mina } \\
\mathbf{t} \_\mathbf{b a c} \\
\mathbf{a}\end{array}$ & $\begin{array}{c}\text { disk } \\
\text { usi }\end{array}$ & No & $\begin{array}{c}\min \\
\text { at_b } \\
\text { aca }\end{array}$ & $\begin{array}{c}\text { disk } \\
\text { usi }\end{array}$ & No & $\begin{array}{c}\min \\
\text { at_b } \\
\text { aca }\end{array}$ & $\begin{array}{c}\text { dis } \\
\text { kus } \\
\text { i }\end{array}$ \\
\hline 1 & 0 & 0 & 37 & 0 & 0 & 73 & 80 & 0 & 109 & 78 & 0 \\
\hline 2 & 0 & 73 & 38 & 0 & 0 & 74 & 0 & 0 & 110 & 0 & 0 \\
\hline 3 & 0 & 0 & 39 & 80 & 0 & 75 & 0 & 0 & 111 & 0 & 73 \\
\hline 4 & 0 & 78 & 40 & 0 & 0 & 76 & 78 & 0 & 112 & 0 & 0 \\
\hline 5 & 81 & 0 & 41 & 0 & 78 & 77 & 0 & 0 & 113 & 90 & 0 \\
\hline 6 & 0 & 0 & 42 & 90 & 0 & 78 & 80 & 70 & 114 & 0 & 0 \\
\hline 7 & 0 & 0 & 43 & 0 & 0 & 79 & 80 & 0 & 115 & 83 & 0 \\
\hline 8 & 0 & 0 & 44 & 0 & 0 & 80 & 78 & 0 & 116 & 0 & 78 \\
\hline 9 & 0 & 0 & 45 & 0 & 0 & 81 & 78 & 76 & 117 & 78 & 0 \\
\hline 10 & 0 & 0 & 46 & 0 & 0 & 82 & 0 & 73 & 118 & 78 & 78 \\
\hline 11 & 0 & 73 & 47 & 0 & 0 & 83 & 78 & 78 & 119 & 0 & 80 \\
\hline 12 & 80 & 0 & 48 & 80 & 0 & 84 & 81 & 74 & 120 & 88 & 0 \\
\hline 13 & 0 & 0 & 49 & 0 & 73 & 85 & 78 & 78 & 121 & 77 & 0 \\
\hline 14 & 0 & 0 & 50 & 0 & 0 & 86 & 0 & 0 & 122 & 79 & 83 \\
\hline 15 & 85 & 0 & 51 & 0 & 79 & 87 & 90 & 0 & 123 & 0 & 0 \\
\hline 16 & 75 & 0 & 52 & 0 & 78 & 88 & 0 & 70 & 124 & 82 & 0 \\
\hline
\end{tabular}


Pengaruh Sosialisasi Pembelajaran Online terhadap Tingkat Keaktifan Siswa SD di Desa Sumberagung Lamongan / Nur Nafi'iyah, Ika Purnama Sari

\begin{tabular}{|c|c|c|c|c|c|c|c|c|c|c|c|}
\hline $\mathbf{1 7}$ & 0 & 0 & $\mathbf{5 3}$ & 95 & 0 & $\mathbf{8 9}$ & 0 & 0 & $\mathbf{1 2 5}$ & 0 & 0 \\
\hline $\mathbf{1 8}$ & 0 & 0 & $\mathbf{5 4}$ & 0 & 82 & $\mathbf{9 0}$ & 0 & 0 & $\mathbf{1 2 6}$ & 0 & 75 \\
\hline $\mathbf{1 9}$ & 0 & 0 & $\mathbf{5 5}$ & 76 & 0 & $\mathbf{9 1}$ & 0 & 0 & $\mathbf{1 2 7}$ & 84 & 0 \\
\hline $\mathbf{2 0}$ & 81 & 0 & $\mathbf{5 6}$ & 0 & 0 & $\mathbf{9 2}$ & 0 & 80 & $\mathbf{1 2 8}$ & 80 & 0 \\
\hline $\mathbf{2 1}$ & 80 & 75 & $\mathbf{5 7}$ & 0 & 0 & $\mathbf{9 3}$ & 80 & 0 & $\mathbf{1 2 9}$ & 80 & 78 \\
\hline $\mathbf{2 2}$ & 0 & 0 & $\mathbf{5 8}$ & 0 & 0 & $\mathbf{9 4}$ & 0 & 78 & $\mathbf{1 3 0}$ & 80 & 0 \\
\hline $\mathbf{2 3}$ & 82 & 0 & $\mathbf{5 9}$ & 0 & 74 & $\mathbf{9 5}$ & 0 & 0 & $\mathbf{1 3 1}$ & 80 & 0 \\
\hline $\mathbf{2 4}$ & 76 & 80 & $\mathbf{6 0}$ & 88 & 0 & $\mathbf{9 6}$ & 0 & 0 & $\mathbf{1 3 2}$ & 0 & 80 \\
\hline $\mathbf{2 5}$ & 79 & 77 & $\mathbf{6 1}$ & 77 & 0 & $\mathbf{9 7}$ & 0 & 0 & $\mathbf{1 3 3}$ & 0 & 0 \\
\hline $\mathbf{2 6}$ & 77 & 73 & $\mathbf{6 2}$ & 0 & 76 & $\mathbf{9 8}$ & 0 & 0 & & & \\
\hline $\mathbf{2 7}$ & 0 & 0 & $\mathbf{6 3}$ & 0 & 0 & $\mathbf{9 9}$ & 80 & 0 & & & \\
\hline $\mathbf{2 8}$ & 80 & 77 & $\mathbf{6 4}$ & 0 & 74 & $\mathbf{1 0 0}$ & 81 & 75 & & & \\
\hline $\mathbf{2 9}$ & 78 & 70 & $\mathbf{6 5}$ & 77 & 0 & $\mathbf{1 0 1}$ & 0 & 80 & & & \\
\hline $\mathbf{3 0}$ & 78 & 80 & $\mathbf{6 6}$ & 0 & 0 & $\mathbf{1 0 2}$ & 0 & 0 & & & \\
\hline $\mathbf{3 1}$ & 0 & 0 & $\mathbf{6 7}$ & 0 & 0 & $\mathbf{1 0 3}$ & 78 & 0 & & & \\
\hline $\mathbf{3 2}$ & 0 & 78 & $\mathbf{6 8}$ & 0 & 78 & $\mathbf{1 0 4}$ & 0 & 80 & & & \\
\hline $\mathbf{3 3}$ & 0 & 0 & $\mathbf{6 9}$ & 83 & 0 & $\mathbf{1 0 5}$ & 0 & 0 & & & \\
\hline $\mathbf{3 4}$ & 0 & 0 & $\mathbf{7 0}$ & 0 & 0 & $\mathbf{1 0 6}$ & 0 & 0 & & & \\
\hline $\mathbf{3 5}$ & 0 & 0 & $\mathbf{7 1}$ & 80 & 0 & $\mathbf{1 0 7}$ & 80 & 0 & & & \\
\hline $\mathbf{3 6}$ & 0 & 0 & $\mathbf{7 2}$ & 0 & 75 & $\mathbf{1 0 8}$ & 80 & 0 & & & \\
\hline
\end{tabular}

\section{Hasil dan Pembahasan}

Tabel 2 merupakan data nilai hasil rekap kegiatan peserta didik dalam membaca dan berdiskusi secara online dalam e-learning. Di mana nilai minat_baca merupakan nilai rata-rata setiap kegiatan membaca materi dasar. Materi yang disampaikan sebanyak 7, dan berdiskusi juga sebanyak 7 kali. Dari masing-masing kegiatan membaca dan berdiskusi kemudian dicari nilai rata-rata sebagaimana tercantum dalam Tabel 3 dan Tabel 4.

Tabel 3 Nilai Masing-masing Minat Baca

\begin{tabular}{|c|c|c|c|c|c|c|c|c|}
\hline No & 1 & 2 & 3 & 4 & 5 & 6 & 7 & $\begin{array}{c}\text { Rata- } \\
\text { rata }\end{array}$ \\
\hline 1 & - & - & - & - & - & - & - & - \\
\hline 2 & - & - & - & - & - & - & - & - \\
\hline 3 & - & - & - & - & - & - & - & - \\
\hline 4 & - & - & - & - & - & - & - & - \\
\hline 5 & 80 & 80 & 80 & 80 & - & - & 85 & 81 \\
\hline 6 & - & - & - & - & - & - & - & - \\
\hline 7 & - & - & - & - & - & - & - & - \\
\hline 8 & - & - & - & - & - & - & - & - \\
\hline 9 & - & - & - & - & - & - & - & - \\
\hline 10 & - & - & - & - & - & - & - & - \\
\hline
\end{tabular}


Amalee: Indonesian Journal of Communily Research and Engagement | Vol. 2 No. 1 (Jan 2021)

\begin{tabular}{|c|c|c|c|c|c|c|c|c|}
\hline 11 & - & - & - & - & - & - & - & - \\
\hline 12 & - & - & 80 & - & - & - & - & 80 \\
\hline 13 & - & - & - & - & - & - & - & - \\
\hline 14 & - & - & - & - & - & - & - & - \\
\hline 15 & 80 & - & - & 90 & - & - & - & 85 \\
\hline 16 & - & 80 & 70 & - & - & - & - & 75 \\
\hline 17 & - & - & - & - & - & - & - & - \\
\hline 18 & - & - & - & - & - & - & - & - \\
\hline 19 & - & - & - & - & - & - & - & - \\
\hline 20 & 80 & 80 & - & 80 & - & - & 85 & 81 \\
\hline 21 & 80 & 80 & 70 & 80 & - & 85 & 85 & 80 \\
\hline 22 & - & - & - & - & - & - & - & - \\
\hline 23 & - & 80 & 80 & 80 & - & 85 & 85 & 82 \\
\hline 24 & - & - & 70 & 80 & - & 70 & 85 & 76 \\
\hline 25 & 85 & 80 & 80 & 80 & - & 80 & 70 & 79 \\
\hline 26 & 70 & 80 & 70 & 80 & - & 80 & 80 & 77 \\
\hline 27 & - & - & - & - & - & - & - & - \\
\hline 28 & - & - & - & 80 & - & - & - & 80 \\
\hline 29 & - & 80 & 70 & 80 & - & - & 80 & 78 \\
\hline 30 & 80 & 80 & 70 & 80 & - & 80 & 80 & 78 \\
\hline 31 & - & - & - & - & - & - & - & - \\
\hline 32 & - & - & - & - & - & - & - & - \\
\hline 33 & - & - & - & - & - & - & - & - \\
\hline 34 & - & - & - & - & - & - & - & - \\
\hline 35 & - & - & - & - & - & - & - & - \\
\hline 36 & - & - & - & - & - & - & - & - \\
\hline 37 & - & - & - & - & - & - & - & - \\
\hline 38 & - & - & - & - & - & - & - & - \\
\hline 39 & 80 & 80 & 80 & 80 & - & 90 & 70 & 80 \\
\hline 40 & - & - & - & - & - & - & - & - \\
\hline 41 & - & - & - & - & - & - & - & - \\
\hline 42 & 90 & - & - & - & - & - & - & 90 \\
\hline 43 & - & - & - & - & - & - & - & - \\
\hline 44 & - & - & - & - & - & - & - & - \\
\hline 45 & - & - & - & - & - & - & - & - \\
\hline 46 & - & - & - & - & - & - & - & - \\
\hline 47 & - & - & - & - & - & - & - & - \\
\hline 48 & 80 & 80 & - & - & - & - & - & 80 \\
\hline 49 & - & - & - & - & - & - & - & - \\
\hline 50 & - & - & - & - & - & - & - & - \\
\hline 51 & - & - & - & - & - & - & - & - \\
\hline 52 & - & - & - & - & - & - & - & - \\
\hline
\end{tabular}


Pengaruh Sosialisasi Pembelajaran Online terhadap Tingkat Keaktifan Siswa SD di Desa Sumberagung Lamongan / Nur Nafi'iyah, Ika Purnama Sari

\begin{tabular}{|c|c|c|c|c|c|c|c|c|}
\hline 53 & - & - & - & 95 & - & - & - & 95 \\
\hline 54 & - & - & - & - & - & - & - & - \\
\hline 55 & - & - & 70 & 80 & - & 85 & 70 & 76 \\
\hline 56 & - & - & - & - & - & - & - & - \\
\hline 57 & - & - & - & - & - & - & - & - \\
\hline 58 & - & - & - & - & - & - & - & - \\
\hline 59 & - & - & - & - & - & - & - & - \\
\hline 60 & 90 & 90 & 70 & 100 & - & - & - & 88 \\
\hline 61 & - & 80 & 80 & - & - & 70 & - & 77 \\
\hline 62 & - & - & - & - & - & - & - & - \\
\hline 63 & - & - & - & - & - & - & - & - \\
\hline 64 & - & - & - & - & - & - & - & - \\
\hline 65 & 80 & 80 & 70 & - & - & - & - & 77 \\
\hline 66 & - & - & - & - & - & - & - & - \\
\hline 67 & - & - & - & - & - & - & - & - \\
\hline 68 & - & - & - & - & - & - & - & - \\
\hline 69 & 90 & 80 & - & - & - & 80 & - & 83 \\
\hline 70 & - & - & - & - & - & - & - & - \\
\hline 71 & 80 & 80 & - & - & - & - & - & 80 \\
\hline 72 & - & - & - & - & - & - & - & - \\
\hline 73 & 80 & - & - & - & - & - & - & 80 \\
\hline 74 & - & - & - & - & - & - & - & - \\
\hline 75 & - & - & - & - & - & - & - & - \\
\hline 76 & - & - & 70 & 80 & - & 90 & 70 & 78 \\
\hline 77 & - & - & - & - & - & - & - & - \\
\hline 78 & 80 & - & - & - & - & - & - & 80 \\
\hline 79 & 80 & 80 & 80 & 80 & - & 80 & - & 80 \\
\hline 80 & 80 & 80 & - & 80 & - & - & 70 & 78 \\
\hline 81 & 80 & 80 & - & 80 & - & - & 70 & 78 \\
\hline 82 & - & - & - & - & - & - & - & - \\
\hline 83 & 80 & 80 & 70 & 80 & - & 80 & - & 78 \\
\hline 84 & 80 & 80 & 70 & 95 & - & 80 & - & 81 \\
\hline 85 & 80 & 80 & 70 & 80 & - & 85 & 70 & 78 \\
\hline 86 & - & - & - & - & - & - & - & - \\
\hline 87 & - & 90 & - & - & - & - & - & 90 \\
\hline 88 & - & - & - & - & - & - & - & - \\
\hline 89 & - & - & - & - & - & - & - & - \\
\hline 90 & - & - & - & - & - & - & - & - \\
\hline 91 & - & - & - & - & - & - & - & - \\
\hline 92 & - & - & - & - & - & - & - & - \\
\hline 93 & 80 & 80 & 80 & 80 & - & 80 & 80 & 80 \\
\hline 94 & - & - & - & - & - & - & - & - \\
\hline
\end{tabular}


Amalee: Indonesian Journal of Communily Research and Engagement | Vol. 2 No. 1 (Jan 2021)

\begin{tabular}{|c|c|c|c|c|c|c|c|c|}
\hline 95 & - & - & - & - & - & - & - & - \\
\hline 96 & - & - & - & - & - & - & - & - \\
\hline 97 & - & - & - & - & - & - & - & - \\
\hline 98 & - & - & - & - & - & - & - & - \\
\hline 99 & 80 & 80 & - & 80 & - & 80 & 80 & 80 \\
\hline 100 & 80 & 80 & 80 & 80 & - & - & 85 & 81 \\
\hline 101 & - & - & - & - & - & - & - & - \\
\hline 102 & - & - & - & - & - & - & - & - \\
\hline 103 & 80 & 70 & 80 & 80 & - & 80 & 80 & 78 \\
\hline 104 & - & - & - & - & - & - & - & - \\
\hline 105 & - & - & - & - & - & - & - & - \\
\hline 106 & - & - & - & - & - & - & - & - \\
\hline 107 & 80 & - & - & 80 & - & - & - & 80 \\
\hline 108 & 80 & 80 & - & - & - & - & - & 80 \\
\hline 109 & 80 & 80 & 80 & 80 & - & 80 & 70 & 78 \\
\hline 110 & - & - & - & - & - & - & - & - \\
\hline 111 & - & - & - & - & - & - & - & - \\
\hline 112 & - & - & - & - & - & - & - & - \\
\hline 113 & 90 & - & - & - & - & - & - & 90 \\
\hline 114 & - & - & - & - & - & - & - & - \\
\hline 115 & 80 & 80 & 80 & 90 & - & 95 & 75 & 83 \\
\hline 116 & - & - & - & - & - & - & - & - \\
\hline 117 & - & 80 & 80 & 80 & - & 80 & 70 & 78 \\
\hline 118 & 80 & 80 & 70 & 80 & - & 80 & 80 & 78 \\
\hline 119 & - & - & - & - & - & - & - & - \\
\hline 120 & 90 & 90 & 80 & 90 & - & 95 & 80 & 88 \\
\hline 121 & 80 & 80 & 70 & 80 & - & 80 & 70 & 77 \\
\hline 122 & 80 & 80 & 80 & 80 & - & 70 & 85 & 79 \\
\hline 123 & - & - & - & - & - & - & - & - \\
\hline 124 & 80 & 90 & 80 & 80 & - & - & 80 & 82 \\
\hline 125 & - & - & - & - & - & - & - & - \\
\hline 126 & - & - & - & - & - & - & - & - \\
\hline 127 & 90 & 90 & 80 & 90 & - & 80 & 75 & 84 \\
\hline 128 & 80 & 80 & - & 80 & - & - & - & 80 \\
\hline 129 & 80 & - & - & - & - & - & - & 80 \\
\hline 130 & 80 & 80 & 80 & 80 & - & 80 & - & 80 \\
\hline 131 & 80 & - & 80 & 80 & - & - & - & 80 \\
\hline 132 & - & - & - & - & - & - & - & - \\
\hline 133 & - & - & - & - & - & - & - & - \\
\hline
\end{tabular}


Tabel 4 Nilai Rekap Diskusi

\begin{tabular}{|c|c|c|c|c|c|c|c|c|}
\hline No & 1 & 2 & 3 & 4 & 5 & 6 & 8 & $\begin{array}{c}\text { Rata- } \\
\text { rata }\end{array}$ \\
\hline 1 & - & - & - & - & - & - & - & - \\
\hline 2 & 70 & - & - & 70 & - & 80 & - & 73 \\
\hline 3 & - & - & - & - & - & - & - & - \\
\hline 4 & - & 80 & 80 & 80 & 75 & 80 & 70 & 78 \\
\hline 5 & - & - & - & - & - & - & - & - \\
\hline 6 & - & - & - & - & - & - & - & - \\
\hline 7 & - & - & - & - & - & - & - & - \\
\hline 8 & - & - & - & - & - & - & - & - \\
\hline 9 & - & - & - & - & - & - & - & - \\
\hline 10 & - & - & - & - & - & - & - & - \\
\hline 11 & - & 70 & - & - & 75 & - & - & 73 \\
\hline 12 & - & - & - & - & - & - & - & - \\
\hline 13 & - & - & - & - & - & - & - & - \\
\hline 14 & - & - & - & - & - & - & - & - \\
\hline 15 & - & - & - & - & - & - & - & - \\
\hline 16 & - & - & - & - & - & - & - & - \\
\hline 17 & - & - & - & - & - & - & - & - \\
\hline 18 & - & - & - & - & - & - & - & - \\
\hline 19 & - & - & - & - & - & - & - & - \\
\hline 20 & - & - & - & - & - & - & - & - \\
\hline 21 & 80 & 70 & 70 & 80 & 75 & 80 & 70 & 75 \\
\hline 22 & - & - & - & - & - & - & - & - \\
\hline 23 & - & - & - & - & - & - & - & - \\
\hline 24 & 80 & 80 & - & - & - & - & - & 80 \\
\hline 25 & 80 & 80 & 70 & 80 & 70 & 80 & 80 & 77 \\
\hline 26 & - & 80 & 70 & 70 & 70 & 80 & 70 & 73 \\
\hline 27 & - & - & - & - & - & - & - & - \\
\hline 28 & 80 & 80 & 70 & 80 & 70 & 90 & 70 & 77 \\
\hline 29 & - & - & 70 & - & - & - & - & 70 \\
\hline 30 & - & 80 & - & - & - & - & - & 80 \\
\hline 31 & - & - & - & - & - & - & - & - \\
\hline 32 & - & - & - & 80 & 75 & 80 & - & 78 \\
\hline 33 & - & - & - & - & - & - & - & - \\
\hline 34 & - & - & - & - & - & - & - & - \\
\hline 35 & - & - & - & - & - & - & - & - \\
\hline 36 & - & - & - & - & - & - & - & - \\
\hline 37 & - & - & - & - & - & - & - & - \\
\hline 38 & - & - & - & - & - & - & - & - \\
\hline 39 & - & - & - & - & - & - & - & - \\
\hline
\end{tabular}


Amalee: Indonesian Journal of Communily Research and Engagement | Vol. 2 No. 1 (Jan 2021)

\begin{tabular}{|c|c|c|c|c|c|c|c|c|}
\hline 40 & - & - & - & - & - & - & - & - \\
\hline 41 & - & 70 & 80 & 80 & 75 & 80 & 80 & 78 \\
\hline 42 & - & - & - & - & - & - & - & - \\
\hline 43 & - & - & - & - & - & - & - & - \\
\hline 44 & - & - & - & - & - & - & - & - \\
\hline 45 & - & - & - & - & - & - & - & - \\
\hline 46 & - & - & - & - & - & - & - & - \\
\hline 47 & - & - & - & - & - & - & - & - \\
\hline 48 & - & - & - & - & - & - & - & - \\
\hline 49 & 70 & 70 & 80 & 70 & - & - & - & 73 \\
\hline 50 & - & - & - & - & - & - & - & - \\
\hline 51 & - & - & 80 & 80 & 75 & 80 & 80 & 79 \\
\hline 52 & - & 80 & 80 & 70 & 80 & 80 & - & 78 \\
\hline 53 & - & - & - & - & - & - & - & - \\
\hline 54 & - & 80 & - & 80 & 80 & 80 & 90 & 82 \\
\hline 55 & - & - & - & - & - & - & - & - \\
\hline 56 & - & - & - & - & - & - & - & - \\
\hline 57 & - & - & - & - & - & - & - & - \\
\hline 58 & - & - & - & - & - & - & - & - \\
\hline 59 & - & 70 & 70 & 80 & 70 & 80 & - & 74 \\
\hline 60 & - & - & - & - & - & - & - & - \\
\hline 61 & - & - & - & - & - & - & - & - \\
\hline 62 & 80 & 70 & 80 & 80 & 70 & 80 & - & 77 \\
\hline 63 & - & - & - & - & - & - & - & - \\
\hline 64 & - & 70 & 80 & 70 & 75 & 80 & 70 & 74 \\
\hline 65 & - & - & - & - & - & - & - & - \\
\hline 66 & - & - & - & - & - & - & - & - \\
\hline 67 & - & - & - & - & - & - & - & - \\
\hline 68 & - & 80 & 80 & 80 & 70 & 80 & - & 78 \\
\hline 69 & - & - & - & - & - & - & - & - \\
\hline 70 & - & - & - & - & - & - & - & - \\
\hline 71 & - & - & - & - & - & - & - & - \\
\hline 72 & - & 70 & - & 70 & 75 & 80 & 80 & 75 \\
\hline 73 & - & - & - & - & - & - & - & - \\
\hline 74 & - & - & - & - & - & - & - & - \\
\hline 75 & - & - & - & - & - & - & - & - \\
\hline 76 & - & - & - & - & - & - & - & - \\
\hline 77 & - & - & - & - & - & - & - & - \\
\hline 78 & - & - & - & - & - & - & 70 & 70 \\
\hline 79 & - & - & - & - & - & - & - & - \\
\hline 80 & - & - & - & - & - & - & - & - \\
\hline 81 & - & 80 & 80 & 70 & 75 & 80 & 70 & 76 \\
\hline
\end{tabular}


Pengaruh Sosialisasi Pembelajaran Online terhadap Tingkat Keaktifan Siswa SD di Desa Sumberagung Lamongan / Nur Nafi'iyah, Ika Purnama Sari

\begin{tabular}{|c|c|c|c|c|c|c|c|c|}
\hline 82 & - & 70 & 70 & 70 & - & 80 & - & 73 \\
\hline 83 & 80 & 70 & 80 & 80 & 75 & 80 & 80 & 78 \\
\hline 84 & 80 & 70 & 70 & 70 & 75 & 80 & - & 74 \\
\hline 85 & - & 80 & - & 70 & - & 90 & 70 & 78 \\
\hline 86 & - & - & - & - & - & - & - & - \\
\hline 87 & - & - & - & - & - & - & - & - \\
\hline 88 & - & - & 70 & - & - & - & - & 70 \\
\hline 89 & - & - & - & - & - & - & - & - \\
\hline 90 & - & - & - & - & - & - & - & - \\
\hline 91 & - & - & - & - & - & - & - & - \\
\hline 92 & - & - & - & 80 & - & 80 & - & 80 \\
\hline 93 & - & - & - & - & - & - & - & - \\
\hline 94 & - & 80 & 80 & 80 & 75 & 80 & 70 & 78 \\
\hline 95 & - & - & - & - & - & - & - & - \\
\hline 96 & - & - & - & - & - & - & - & - \\
\hline 97 & - & - & - & - & - & - & - & - \\
\hline 98 & - & - & - & - & - & - & - & - \\
\hline 99 & - & - & - & - & - & - & - & - \\
\hline 100 & - & - & - & 70 & - & 80 & - & 75 \\
\hline 101 & - & - & - & 70 & - & - & 90 & 80 \\
\hline 102 & - & - & - & - & - & - & - & - \\
\hline 103 & - & - & - & - & - & - & - & - \\
\hline 104 & - & 80 & 80 & - & - & - & - & 80 \\
\hline 105 & - & - & - & - & - & - & - & - \\
\hline 106 & - & - & - & - & - & - & - & - \\
\hline 107 & - & - & - & - & - & - & - & - \\
\hline 108 & - & - & - & - & - & - & - & - \\
\hline 109 & - & - & - & - & - & - & - & - \\
\hline 110 & - & - & - & - & - & - & - & - \\
\hline 111 & - & 70 & 80 & 70 & - & - & - & 73 \\
\hline 112 & - & - & - & - & - & - & - & - \\
\hline 113 & - & - & - & - & - & - & - & - \\
\hline 114 & - & - & - & - & - & - & - & - \\
\hline 115 & - & - & - & - & - & - & - & - \\
\hline 116 & - & 80 & 80 & 70 & - & 80 & - & 78 \\
\hline 117 & - & - & - & - & - & - & - & - \\
\hline 118 & - & 80 & 80 & 70 & - & 80 & 80 & 78 \\
\hline 119 & - & - & - & 80 & - & - & - & 80 \\
\hline 120 & - & - & - & - & - & - & - & - \\
\hline 121 & - & - & - & - & - & - & - & - \\
\hline 122 & - & 80 & 80 & 80 & 80 & 90 & 90 & 83 \\
\hline 123 & - & - & - & - & - & - & - & - \\
\hline
\end{tabular}




\begin{tabular}{|c|c|c|c|c|c|c|c|c|}
\hline $\mathbf{1 2 4}$ & - & - & - & - & - & - & - & - \\
\hline $\mathbf{1 2 5}$ & - & - & - & - & - & - & - & - \\
\hline $\mathbf{1 2 6}$ & - & 80 & - & 70 & - & 80 & 70 & 75 \\
\hline $\mathbf{1 2 7}$ & - & - & - & - & - & - & - & - \\
\hline $\mathbf{1 2 8}$ & - & - & - & - & - & - & - & - \\
\hline $\mathbf{1 2 9}$ & - & 80 & 80 & 80 & 75 & 80 & 70 & 78 \\
\hline $\mathbf{1 3 0}$ & - & - & - & - & - & - & - & - \\
\hline $\mathbf{1 3 1}$ & - & - & - & - & - & - & - & - \\
\hline $\mathbf{1 3 2}$ & - & 80 & - & - & - & - & - & 80 \\
\hline $\mathbf{1 3 3}$ & - & - & - & - & - & - & - & - \\
\hline
\end{tabular}

Tabel 4 merupakan rekap setiap kegiatan diskusi, dan jumlah diskusi sebanyak 7 kali, dan dari nilai masing-masing diskusi dirata-rata. Selanjutnya dari nilai diskusi dan minat baca dihitung nilai korelasi. Untuk menghitung nilai korelasi peneliti menggunakan bantuan fungsi correl dalam Excel. Yang dicari nilai korelasi adalah keaktifan membaca terhadap diskusi. Nilai korelasi antara keaktifan membaca terhadap diskusi adalah -0,024. Artinya tidak ada hubungan antara keaktifan membaca siswa terhadap berdiskusi.

Siswa yang ikut aktif dalam membaca materi belum tentu aktif berdiskusi. Ataupun sebaliknya siswa yang aktif berdiskusi belum tentu aktif membaca materi. Dari 133 siswa, yang aktif membaca sebanyak 53 siswa, dan yang aktif berdiskusi sebanyak 41 siswa. Dan siswa yang keduanya aktif baik membaca materi maupun berdiskusi sebanyak 16 siswa.

\section{Kesimpulan}

Dapat diambil kesimpulan bahwa berdasarkan data dapat diketahui siswa yang aktif membaca materi hanya 40\% dari 133 siswa. Sedangkan siswa yang aktif berdiskusi hanya $31 \%$ dari 133 siswa. Selanjutnya yang aktif keduanya baik membaca dan berdiskusi hanya $12 \%$ dari 133 siswa. Jadi dari data tersebut bisa disimpulkan bahwa pembelajaran online terhadap tingkat keaktifan siswa SD Desa Sumberagung Mantup masih kurang efektif. Perlu adanya pedoman pembelajaran online dan metode instruksi khusus dari Guru SD agar pembelajaran online lebih efektif. Bisa juga dievaluasi untuk anak tingkat SD apakah memang tidak tepat (belum cocok) menggunakan pembelajaran online dan lebih cocok dan efektif menggunakan pembelajaran secara luring.

\section{Pernyataan}

Terima kasih banyak kepada masyarakat dan para pemuda dan pelajar di Desa Sumberagung Kecamatan Mantup Kabupaten Lamongan. Masyarakat yang bersedia ditempati dan memberikan fasilitas untuk melakukan kegiatan KKN (Kuliah Kerja Nyata). Dan terima kasih juga kepada Universitas Islam Lamongan yang memberikan kesempatan dan kepercayaan kepada kami untuk menjadi pembimbing lapangan $\mathrm{KKN}$. 


\section{Referensi}

Ardiansyah, A., \& Asfiyak, K. (2020). Pelatihan Merancang dan Mengembangkan Multimedia Pembelajaran untuk Guru di SD Negeri Bajangan Kabupaten Pasuruan. Amalee: Indonesian Journal of Community Research and Engagement, 1(2), 125-137. https://doi.org/10.37680/amalee.v1i2.368

Hanum, N. S. (2013). Keefektifan e-Learning Sebagai Media Pembelajaran (Studi Evaluasi Model Pembelajaran e-Learning SMK Telkom Sandhy Putra Purwokerto). Jurnal Pendidikan Vokasi, 90-102. https://doi.org/10.21831/jpv.v3i1.1584

Purnama, M. N. A. (2020). Blended Learning Sebagai Sarana Optimalisasi Pembelajaran Daring Di Era New Normal. SCAFFOLDING: Jurnal Pendidikan Islam dan Multikulturalisme, 2(02), 106-121. https://doi.org/10.37680/scaffolding.v2i02.535

Putranti, N. (2013). Cara Membuat Media Pembelajaran Online Menggunakan Edmodo. Jurnal Pendidikan Informatika dan Sains, 139-147. http://dx.doi.org/10.31571/saintek.v2i2.224

Setemen, K. (2010). Pengembangan Evaluasi Pembelajaran Online. Jurnal Pendidikan dan Pengajaran, 207-214. http://dx.doi.org/10.23887/jppundiksha.v43i3.124

Yuberti. (2015). Online Group Discussion Pada Mata Kuliah Teknologi Pembelajaran Fisika. Jurnal Ilmiah Pendidikan Fisika Al-BiRuNi, 145-153. https://doi.org/10.24042/jpifalbiruni.v4i2.88

Yudie Irawan, Nanik Susanti, Wiwit Agus Triyanto. (2015). Analisa Dan Perancangan Sistem Pembelajaran Online (e-Learning) Pada Smk Mambaul Falah Kudus. SIMETRIS, 345-352. https://doi.org/10.24176/simet.v6i2.471 